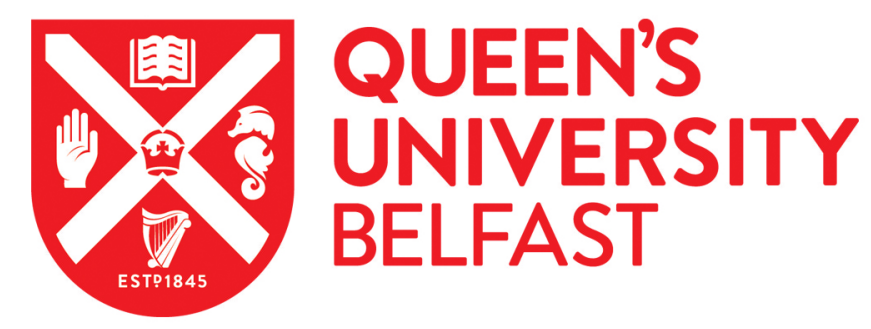

\title{
Modelling the correlation between processing parameters and properties in titanium alloys using artificial neural network
}

Malinov, S., Sha, W., \& McKeown, J. J. (2001). Modelling the correlation between processing parameters and properties in titanium alloys using artificial neural network. Computational Materials Science, 21(3)(3), 375-394. https://doi.org/10.1016/S0927-0256(01)00160-4

Published in:

Computational Materials Science

Queen's University Belfast - Research Portal:

Link to publication record in Queen's University Belfast Research Portal

\section{General rights}

Copyright for the publications made accessible via the Queen's University Belfast Research Portal is retained by the author(s) and / or other copyright owners and it is a condition of accessing these publications that users recognise and abide by the legal requirements associated with these rights.

Take down policy

The Research Portal is Queen's institutional repository that provides access to Queen's research output. Every effort has been made to ensure that content in the Research Portal does not infringe any person's rights, or applicable UK laws. If you discover content in the Research Portal that you believe breaches copyright or violates any law, please contact openaccess@qub.ac.uk. 


\title{
Modelling the correlation between processing parameters and properties in titanium alloys using artificial neural network
}

\author{
S. Malinov, W. Sha *, J.J. McKeown \\ School of Civil Engineering, The Queen's University, David Keir Building, Belfast, Northern Ireland BT7 1NN, UK
}

\begin{abstract}
A model is developed for the analysis and prediction of the correlation between processing (heat treatment) parameters and mechanical properties in titanium alloys by applying artificial neural network (ANN). The input parameters of the neural network $(\mathrm{NN})$ are alloy composition, heat treatment parameters and work (test) temperature. The outputs of the NN model are nine most important mechanical properties namely ultimate tensile strength, tensile yield strength, elongation, reduction of area, impact strength, hardness, modulus of elasticity, fatigue strength and fracture toughness. The model is based on multilayer feedforward neural network. The NN is trained with comprehensive dataset collected from both the Western and Russian literature. A very good performance of the neural network is achieved. Some explanation of the predicted results from the metallurgical point of view is given. The model can be used for the prediction of properties of titanium alloys at different temperatures as functions of processing parameters and heat treatment cycle. It can also be used for the optimization of processing and heat treatment parameters. Graphical user interface (GUI) is developed for use of the model. (c) 2001 Elsevier Science B.V. All rights reserved.
\end{abstract}

PACS: $62.20 .-\mathrm{x}$

Keywords: Titanium alloys; Mechanical properties; Modelling; Computer simulation; Neural network; Optimization

\section{Introduction}

A generic class of titanium-based materials has been developed over the past years. Titanium and its alloys are currently finding widespread applications in many industries due to their desirable and versatile combination of properties. The advantages of titanium alloys include: (i) low densities, which give very attractive strength to weight ratios allowing lighter and stronger structures; (ii) superior corrosion and erosion resistance in many

\footnotetext{
${ }^{*}$ Corresponding author. Tel.: +44-28-90-274017; fax: +44-2890-663754.

E-mail address: w.sha@qub.ac.uk (W. Sha).
}

environments; (iii) high temperature capability. Although the titanium materials are still considered as expensive materials, for many applications the cost of titanium alloys can be justified on the basis of their desirable properties.

The mechanical properties and the application of titanium alloys depend essentially on the characteristics of the microstructure [1-4]. The final microstructure is formed during heat and/or thermomechanical processing. It is therefore important to understand the correlation "processing parameters $\Rightarrow$ microstructure $\Rightarrow$ properties", which would allow the optimization of the processing parameters and alloy compositions in order to achieve the desired combination of properties for any particular 
application. At present this is one of the most challenging areas in the field of research on titanium alloys. It must be pointed out, however, that the relationship between the processing parameters and the mechanical properties for titanium alloys has so far only been studied empirically which is both costly and time consuming. Computer modelling of the correlation "processing parameters-mechanical properties" has not yet been widely used for titanium alloys. There is limited work [5-9] on physical modelling of phase transformations in Ti-alloys.

Artificial neural networks (ANN), on the other hand, are currently one of the most powerful modelling techniques based on a statistical approach. There has been only limited work on the application of neural networks (NNs) in the field of titanium alloys [10]. Neural network modelling is suitable for simulations of correlations which are hard to describe by physical models. For reliable neural network modelling a significant amount of data as well as powerful computing resources are necessary; but once the model artificial neural network has been created it can be run conveniently on almost any computer. A huge amount of data on mechanical properties of titanium alloys at different conditions is currently available in the literature [1-4,11-16]. These data are sometimes rather confusing for use in the engineering practice.

In the present work we aim to design an artificial neural network for the prediction of the me- chanical properties of titanium alloys as functions of the processing parameters and alloy composition. The work was motivated by the desire to create a tool for optimization of the processing parameters and the alloy composition.

\section{Model description}

Following the main aim of this work a most general scheme of the model is given in Fig. 1. The input parameters of the neural network are alloy composition, heat treatment parameters and work (test) temperature. The composition includes the most commonly used alloying elements in titanium alloys, namely Al, Mo, Sn, Zr, V, Cr, Fe, Cu, Bi, $\mathrm{Si}, \mathrm{Nb}, \mathrm{Ta}, \mathrm{Mn}$ and $\mathrm{O}$. Typical heat treatments of titanium alloys are taken into account: (i) annealing in $\alpha, \alpha+\beta$ and $\beta$ regions; (ii) solution treatment in $\beta$ and $\alpha+\beta$ regions followed by ageing at different temperatures; (iii) duplex annealing. Since the titanium alloys are considered as desirable and sometimes essential for many structural applications in high temperatures the test/ work temperature is included as another input in the model. In this way the model is extended to trace the correlation "processing parametersworking conditions (temperature)-mechanical properties".

The outputs of the neural network model are the nine most important mechanical properties

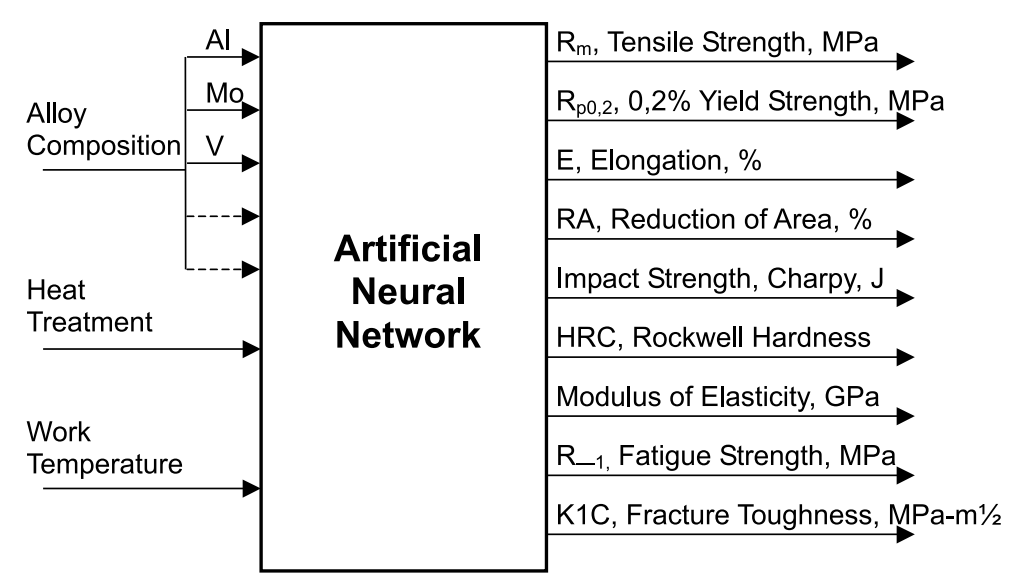

Fig. 1. Schematic model of artificial neural network for prediction of mechanical properties for titanium alloys. 
namely ultimate tensile strength, tensile yield strength, elongation, reduction of area, impact strength, hardness, modulus of elasticity, fatigue strength and fracture toughness.

\subsection{Basic principles of the neural networks}

Artificial neural network modelling is a relatively new technique. It is essentially a "black box" operation linking input data to output data using a particular set of nonlinear basis functions. Since artificial neural network modelling is a nonlinear statistical technique, it can be used to solve problems that are not amenable to conventional statistical methods. In the past few years there has been a constantly increasing interest in neural network modelling in different fields of materials science [10,17-28].

Artificial neural networks consist of simple synchronous processing elements, which are inspired by biological nervous systems [29]. The basic unit in the artificial neural network is the neuron. Neurons are connected to each other by links known as synapses; associated with each synapse there is a weight factor. Usually neural networks are trained so that a particular set of inputs produces, as nearly as possible, a specific set of target outputs. The training procedure is described in Section 2.3. In the present work feedforward hierarchical artificial neural networks are used. The model is shown schematically in Fig. 2. In feedforward neural networks the information is processed in one direction - from input to output - and the neurons are ordered in layers. The numbers of neurons in the input layer and the output layer are determined by the numbers of input and output parameters, respectively.

Commonly, neural network modelling follows these steps: database collection; analysis and preprocessing of the data; training of the neural network. The latter includes the choice of architecture, training functions, training algorithms and parameters of the network; testing of the trained network; and using the trained neural network for simulation and prediction. The model developed here has adopted these steps.

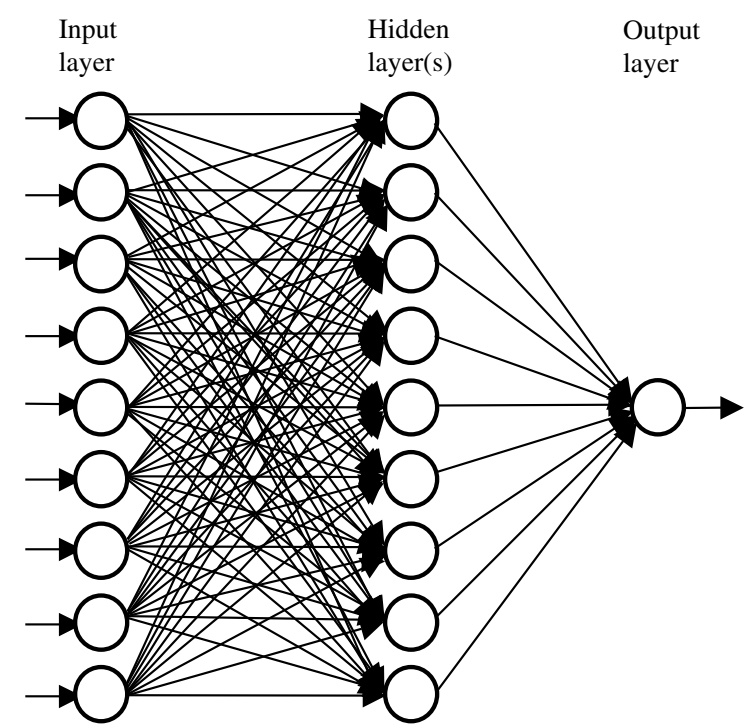

Fig. 2. A model of feedforward hierarchical artificial neural network.

\subsection{Dataset and inputloutput parameters}

A network is usually trained using a large number of input with corresponding output data (input/output pairs). That means that for reliable training and performance of any neural network we need an appropriate database. Using such a database we can train neural network to perform complex functions.

The database was constructed by collecting available data on mechanical properties for titanium alloys at different heat treatment conditions and working temperatures [1-4,11-16]. In total 764 input/output data pairs for different titanium alloys were collected from both the Western and Russian literature. All data were used fully or partly in the training procedure. Most of the data were for commercial Ti alloys (see Appendix A for list of the alloys used).

The selection of the input parameters is a very important aspect of neural network modelling. Usually this choice is based on the physical background of a process. All relevant input parameters must be represented as the input data of the neural network. It is known that the training of an artificial neural network requires a large number of input/output pairs, and this can lead to lengthy 
training times. Therefore, before training the number of actual input parameters should be restricted by ignoring the linearly dependent input parameters.

In the present work the following were used as input parameters:

\subsubsection{Alloy composition}

After preprocessing analysis the 14 alloying elements initially chosen (see above) were reduced to 11 , namely $\mathrm{Al}, \mathrm{Mo}, \mathrm{Sn}, \mathrm{Zr}, \mathrm{Cr}, \mathrm{Fe}, \mathrm{V}, \mathrm{Si}, \mathrm{Nb}, \mathrm{Mn}$ and $\mathrm{O} . \mathrm{Cu}, \mathrm{Bi}$ and $\mathrm{Ta}$ were contained in only one alloy, Ti-2.5Cu(IMI230), Ti-6Al-2Sn-1.5Zr$1 \mathrm{Mo}-0.35 \mathrm{Bi}-0.1 \mathrm{Si}$ and $\mathrm{Ti}-6 \mathrm{Al}-2 \mathrm{Nb}-1 \mathrm{Ta}-0.8 \mathrm{Mo}$, respectively, at different conditions and temperatures. The data pairs containing $\mathrm{Cu}$ and $\mathrm{Bi}$ were excluded from the training database while $\mathrm{Ta}$, where present, was converted to $\mathrm{Nb}$ equivalent. When oxygen level of the alloy was unknown an amount of $0.15 \mathrm{wt} \%$ was attributed. Modelling of the oxygen influence on the mechanical properties was based on 61 data pairs with oxygen content above $0.2 \mathrm{wt} \%$ or below $0.1 \mathrm{wt} \%$ (ELI alloys). For the remaining part of the database the oxygen content was in the range $0.1-0.2 \mathrm{wt} \%$. When $\mathrm{Fe}$ was not an alloying element in the titanium alloy an amount of $0.15 \mathrm{wt} \%$ was attributed. Analysis of the database in terms of the alloy elements present is given in Table 1.

\subsubsection{Heat treatment}

Nine classical heat treatment types for titanium alloys for which data in the literature exist were taken into account in the neural network model. Since neural networks operate with digits the heat treatments were digitized by means of attributing different digits to the different heat treatments. The heat treatment used and the corresponding digits are given in Table 2. The distribution of the inputs within the corresponding range is another very important characteristic of the data set since it gives information about intervals where we can achieve higher or lower accuracy of training and prediction. The distribution in terms of the heat treatments is presented in Table 2 showing the number of the data pairs corresponding to each type of heat treatment. The large amount of data is available for the two most popular heat treatments of titanium alloys, namely annealing in the $\alpha+\beta$ field and solution treatment in the $\alpha+\beta$ field followed by ageing.

\subsubsection{Temperature}

Most of the data on the different mechanical properties were at room temperature (see Fig. 3). However, there were a lot of data at temperatures $-193^{\circ} \mathrm{C},-70^{\circ} \mathrm{C},-62^{\circ} \mathrm{C}, 20^{\circ} \mathrm{C}, 100^{\circ} \mathrm{C}, 200^{\circ} \mathrm{C}$, $300^{\circ} \mathrm{C}, 316^{\circ} \mathrm{C}, 350^{\circ} \mathrm{C}, \quad 400^{\circ} \mathrm{C}, \quad 427^{\circ} \mathrm{C}, \quad 450^{\circ} \mathrm{C}$, $480^{\circ} \mathrm{C}, 500^{\circ} \mathrm{C}, 538^{\circ} \mathrm{C}, 550^{\circ} \mathrm{C}$ and $600^{\circ} \mathrm{C}$. Some

Table 1

Analysis of the chemical composition of the alloys used for training and test

\begin{tabular}{|c|c|c|c|c|c|c|c|c|c|c|c|c|c|c|}
\hline Element & $\mathrm{Al}$ & Mo & Sn & $\mathrm{Zr}$ & $\mathrm{Cr}$ & $\mathrm{Fe}$ & $\mathrm{V}$ & $\mathrm{Cu}^{\mathrm{a}, \mathrm{b}}$ & $\mathrm{Bi}^{\mathrm{c}, \mathrm{b}}$ & $\mathrm{Si}$ & $\mathrm{Nb}$ & $\mathrm{Ta}^{\mathrm{d}, \mathrm{e}}$ & $\mathrm{Mn}$ & $\mathrm{O}$ \\
\hline $\begin{array}{l}\text { Number of data } \\
\text { pairs containing } \\
\text { this element }\end{array}$ & 699 & 467 & 247 & 275 & 163 & $175^{\mathrm{f}}$ & 272 & 3 & 7 & 150 & 105 & 39 & 21 & $61^{\mathrm{g}}$ \\
\hline Minimum (wt\%) & 0 & 0 & 0 & 0 & 0 & 0.15 & 0 & 2.50 & 0.35 & 0 & 0 & 1.00 & 0 & 0.05 \\
\hline Maximum (wt $\%)$ & 8.00 & 15.00 & 11.00 & 11.00 & 11.00 & 5.00 & 16.00 & 2.50 & 0.35 & 0.50 & 7.00 & 1.00 & 8.00 & 0.33 \\
\hline Mean & 4.91 & 4.89 & 3.38 & 4.73 & 4.78 & 1.36 & 6.49 & 2.50 & 0.35 & 0.20 & 1.98 & 1.00 & 4.90 & 0.16 \\
\hline S.D. & 1.69 & 4.70 & 2.08 & 2.78 & 3.63 & 0.92 & 4.32 & 0.00 & 0.00 & 0.11 & 0.89 & 0.00 & 3.33 & 0.09 \\
\hline
\end{tabular}

${ }^{\text {a }}$ Only in one alloy (Ti-2.5Cu(IMI230)).

${ }^{\mathrm{b}}$ Excluded from the data set.

${ }^{\mathrm{c}}$ Only in one alloy (Ti-6Al-2Sn-1.5Zr-1Mo-0.35Bi-0.1Si).

${ }^{\mathrm{d}}$ Only in one alloy (Ti-6Al-2Nb-1Ta-0.8Mo).

${ }^{\mathrm{e}}$ Converted to $\mathrm{Nb}$.

${ }^{\mathrm{f}}$ Number of data pairs containing $\mathrm{Fe}$ as an alloying element.

${ }^{\mathrm{g}}$ Number of data pairs containing oxygen different from the usual. 
Table 2

Heat treatments used in the database and their digitizing

\begin{tabular}{lcl}
\hline Heat treatment & $\begin{array}{l}\text { Number } \\
\text { of data } \\
\text { pairs }\end{array}$ & Digitizing \\
\hline Without heat treatment & 16 & 0 \\
Annealing $(\beta)$ & 45 & 1 \\
Annealing $(\alpha+\beta)$ & 237 & 2 \\
Annealing $(\alpha)$ & 29 & 3 \\
Solution treatment $(\beta)$ & 18 & 4 \\
Solution treatment $(\alpha+\beta)$ & 13 & 5 \\
Solution treatment & 29 & $6+\left(1-T_{\text {ag }} / T_{\text {transus }}\right)$ \\
$(\beta)+$ ageing & & \\
Solution treatment & 247 & $7+\left(1-T_{\text {ag }} / T_{\text {transus }}\right)$ \\
$(\alpha+\beta))+$ ageing & & \\
Duplex annealing & 130 & 8 \\
\hline
\end{tabular}

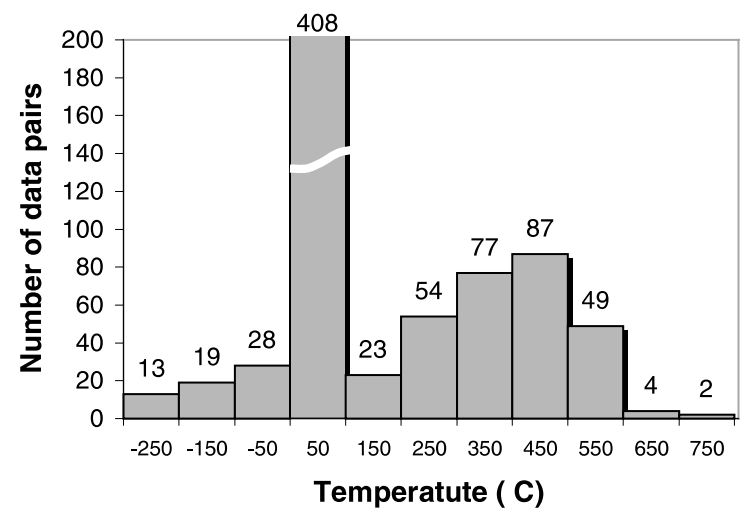

Fig. 3. Distribution of the database on mechanical properties of titanium alloys versus test/working temperature.

data for mechanical properties at very low $\left(-253^{\circ} \mathrm{C}\right)$ as well as at very high $\left(800^{\circ} \mathrm{C}\right)$ temperatures were collected. The analysis of the database distribution in terms of the test/work temperature is present in Fig. 3 in a form of histogram showing the number of the data pairs in each temperature interval. This analysis gives us a confidence that our model can work with sufficient accuracy within a temperature interval of $-100^{\circ} \mathrm{C}$ to $+600^{\circ} \mathrm{C}$.

Different numbers of data pairs for the different mechanical properties were collected. Analysis of the database regarding the outputs is presented in Table 3. Most of the data collected were for tensile test properties but there were also data for the other mechanical properties. The ranges of varying of the properties as well as the conditions at which data with respect to the alloy composition, heat treatment and temperature existed are shown in Table 3.

\subsection{Neural network training}

The process of fitting the network to the experimental data is called training. It consists of adjusting the weight associated with each connection (synapse) between neurons. The weight of a synapse, multiplied by the strength of the signal on that synapse, defines the contribution of that synapse to the activation of the neuron for which it is an input. The total activation of a neuron is then the sum of the activations of all its inputs, and this defines the value of the output signal for that neuron, via a transfer function. Transfer functions are generally s-shaped (sigmoid) curves, with the output value confined within limits such as $(0,1)$ or $(-1 / 2,1 / 2)$. The choice of transfer function is one of the decisions which must be made by the user, although it is not usually a very critical factor. The most popular functions are: Hard limit (hardlim $\left.{ }^{1}\right), \quad \log$ sigmoid $\left(\operatorname{logsig}^{1}\right), \quad$ Linear (purelin ${ }^{1}$ ), Hyperbolic tangent sigmoid (tansig ${ }^{1}$ ).

By adjusting the values of synaptic weights throughout the network, the outputs of the artificial neural network for any given set of inputs can be altered. Training consists of adjusting the weights until the outputs for each set of data inputs are as close as possible to the data outputs; i.e., until the network correctly simulates the known behaviour of the system to be modelled. The simulation will rarely be exact; training is usually aimed at minimizing the sum of the squares of the differences between predicted and measured values of the outputs.

It became standard for some years to train artificial neural networks by a method called Backpropagation. This consisted of assigning a random initial set of weights to the artificial neural network, then presenting the data inputs, one set at a time, and adjusting the weights so as to reduce the corresponding output error. This was repeated for each set of data, and then the complete cycle was

\footnotetext{
${ }^{1}$ Neural network toolbox for MATLAB commands for the realization of the corresponding transfer functions.
} 


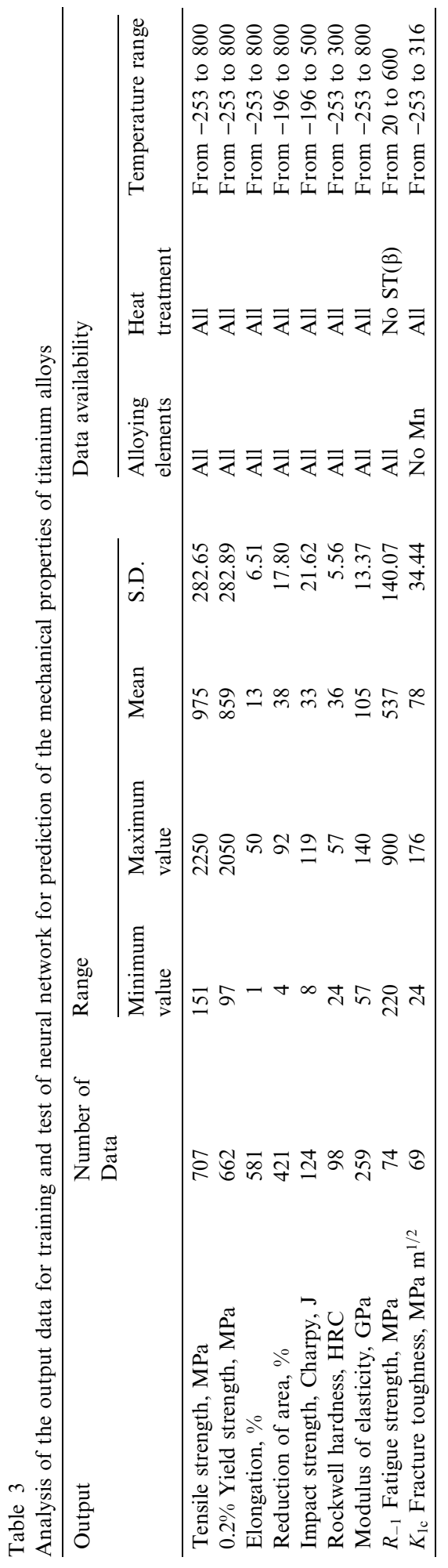

iterated until an acceptably low value of the sum of squares of errors was achieved. The method suffers from the drawback that the adjustments which reduce the errors on a given set of data, may increase the errors on the other sets of data, so the process is constantly undoing the improvements made so far. The result is a method which is both inefficient and unreliable, requiring many iterations to converge if it converges at all.

A much better approach has turned out to be to use one of the many methods of numerical optimization which have been developed for solving nonlinear sums-of-squares problems [30,31]. (The nonlinearity arises because the relationships between outputs and weights of an artificial neural network are nonlinear, although well defined. It is this nonlinearity which makes it necessary to use iterative methods.) The most efficient method in most cases is the Gauss-Newton algorithm; but this method can suffer from numerical instability unless the initial estimate of the weights is fairly accurate. On the other hand, the method of Steepest Descent is reliable but highly inefficient. (In fact, Backpropagation becomes equivalent to Steepest Descent when adjustments are made, not for each error separately, but to all at once - so-called Batch-Backpropagation.) The method used for this study was the Levenburg-Marquardt algorithm, which can be regarded as a compromise between Gauss-Newton and Steepest Descent, heavily favouring the former. Typically, the use of Levenberg-Marquardt leads to a reduction of orders of magnitude in the number of training iterations required compared with Backpropagation, and is highly reliable.

In this work the neural network models were designed and trained using the MATLAB 5.3 ${ }^{\circledR} 2$ package. Standard multilayer feedforward networks (see Fig. 2) were created. The general model of the neural network (Fig. 1) consisted of separate networks for each mechanical property.

Before the training of the network both input and output variables were normalized within the range -1 to 1 as follows:

\footnotetext{
${ }^{2}$ The Math Works, Inc. product, Neural Network Toolbox Version 3 for MATLAB 5.3 (R11).
} 
$x_{N}=2 \frac{x-x_{\min }}{x_{\max }-x_{\min }}-1$,

where $x_{N}$ is the normalized value of a certain parameter, $x$ is the measured value for this parameter, $x_{\min }$ and $x_{\max }$ are the minimum and the maximum values in the database for this parameter, respectively.

For all created neural networks the general structure of input, one hidden and one output layer was used. In order to determine the optimal architecture, several neural networks were trained

Table 4

Correlation coefficient between predicted properties from the neural network and experimental properties for the different datasets and training options

\begin{tabular}{|c|c|c|c|c|c|c|}
\hline \multirow{2}{*}{$\begin{array}{l}\text { Training } \\
\text { Number of hidden layers }\end{array}$} & \multicolumn{4}{|c|}{$\begin{array}{l}\text { Bayesian regularization in combination } \\
\text { with Levenberg-Marquardt training }\end{array}$} & \multirow{2}{*}{$\begin{array}{l}\text { Levenberg-Marquardt } \\
\text { training without } \\
\text { regularization }\end{array}$} & \multirow{2}{*}{$\begin{array}{l}\text { Training against } \\
\text { validation set }\end{array}$} \\
\hline & One & One & Two & One & & \\
\hline $\begin{array}{l}\text { Number of neurons in the } \\
\text { hidden layer }\end{array}$ & 13 & 13 & 13 & 26 & 13 & 13 \\
\hline Training function & tansig & logsig & tansig & tansig & tansig & tansig \\
\hline \multicolumn{7}{|l|}{ Tensile strength } \\
\hline Train & 0.970 & & & & 0.835 & \\
\hline Test & 0.963 & & & & 0.747 & \\
\hline Whole & 0.968 & 0.967 & 0.970 & 0.965 & 0.805 & 0.955 \\
\hline \multicolumn{7}{|l|}{$0.2 \%$ Yield strength } \\
\hline Train & 0.974 & & & & 0.982 & \\
\hline Test & 0.971 & & & & 0.866 & \\
\hline Whole & 0.973 & 0.970 & 0.976 & 0.974 & 0.947 & 0.955 \\
\hline \multicolumn{7}{|l|}{ Elongation } \\
\hline Train & 0.898 & & & & 0.908 & \\
\hline Test & 0.877 & & & & 0.548 & \\
\hline Whole & 0.891 & 0.881 & 0.895 & 0.886 & 0.783 & 0.760 \\
\hline \multicolumn{7}{|l|}{ Reduction of area } \\
\hline Train & 0.907 & & & & 0.954 & \\
\hline Test & 0.891 & & & & 0.396 & \\
\hline Whole & 0.901 & 0.887 & 0.899 & 0.900 & 0.599 & 0.867 \\
\hline \multicolumn{7}{|l|}{ Impact strength } \\
\hline Train & 0.985 & & & & 0.994 & \\
\hline Test & 0.972 & & & & 0.406 & \\
\hline Whole & 0.980 & 0.967 & 0.948 & 0.928 & 0.517 & 0.866 \\
\hline \multicolumn{7}{|l|}{ Rockwell hardness } \\
\hline Train & 0.961 & & & & 0.982 & \\
\hline Test & 0.928 & & & & 0.209 & \\
\hline Whole & 0.953 & 0.948 & 0.932 & 0.950 & 0.294 & 0.846 \\
\hline \multicolumn{7}{|l|}{ Modulus of easticity } \\
\hline Train & 0.975 & & & & 0.910 & \\
\hline Test & 0.971 & & & & 0.795 & \\
\hline Whole & 0.973 & 0.974 & 0.977 & 0.973 & 0.863 & 0.927 \\
\hline \multicolumn{7}{|l|}{ Fatigue strength } \\
\hline Train & 0.976 & & & & 0.991 & \\
\hline Test & 0.965 & & & & 0.073 & \\
\hline Whole & 0.971 & 0.627 & 0.972 & 0.609 & 0.377 & 0.612 \\
\hline \multicolumn{7}{|l|}{ Fracture toughness } \\
\hline Train & 0.508 & & & & 0.994 & \\
\hline Test & 0.115 & & & & 0 & \\
\hline Whole & 0.438 & 0.422 & 0.438 & 0.437 & 0 & 0.816 \\
\hline
\end{tabular}


with different number of neurons in the hidden layer and different transfer functions (see Table 4). The results from the artificial neural network with the best result for each case are shown here. In the general case these models include 13 neurons in the input layer, 13 neurons in the hidden layer and 1 neuron in the output layer. For all cases a linear transfer function (purelin) was used in the output layers. In the hidden layers "tangent sigmoid transfer function (tansig)" and "log sigmoid transfer function (logsig)" were attempted (see Table 4). When the logsig was applied, the inputs and the outputs were normalized to within the range $0-1$ using an equation similar to Eq. (1).

The most accurate predictions of the neural networks were obtained with hyperbolic tangent sigmoid transfer function

$f(x)=\frac{2}{1+\mathrm{e}^{-2 x}}-1$

for the neurons in the hidden layer and with linear transfer function for the neurons in the output layer.

The networks were automatically initialized with the default parameters. In order to achieve the best result, different training options have been attempted including training on variations of mean square error for better generalization, training against a validation set, and training until the gradient of the error reaches a minimum. Improving of the generalization has been attempted by means of "regularization" and "early stopping with validation". Finally, automated regularization based on the Bayesian regularization in combination with the Levenberg-Marquardt training was chosen.

Before training the data set was randomly divided into two groups. Two-thirds of the data were used for training and one-third for test. When the training was performed against a validation set, the groups were as follows: one-half training set, one-quarter - validation set and onequarter - test set. The training program was written in a way that each time when the program is run a new random distribution of the whole data set into the above subdatasets is executed. By varying all the parameters described above trained neural networks with the best performance were achieved.

\subsection{Neural network performance and test}

After the training the neural network performance was checked. The results from the trained neural networks with the best result for each mechanical property are shown here. The performance of the neural network for prediction of tensile strength of titanium alloys is demonstrated in Fig. 4. The diagrams show an analysis of the network response in a form of linear regression analysis between the network outputs (predictions) and the corresponding targets (experimental data) for the different datasets. It is obvious that the predicted values from the trained neural network outputs track the targets very well. Acceptable performances were achieved in the neural networks for the other mechanical properties (see Appendix B). The correlation coefficient $(R)$ values for all cases of training/test datasets and different training techniques used are shown in Table 4. A good performance of the neural network has been achieved and the network can be used for further simulations and predictions.

Additionally we reproved the performance accuracy by statistical analysis of the error of neural network predictions (Fig. 5). For the test dataset neural network predictions were calculated. These were compared with the corresponding experimental values. Thereafter the relative errors were calculated using

Error $=\frac{\mathrm{Rm}_{\mathrm{EXP}}-\mathrm{Rm}_{\mathrm{NN}}}{\mathrm{R} \mathrm{m}_{\mathrm{EXP}}} \times 100 \%$,

where $\mathrm{Rm}_{\text {EXP }}$ is the experimental (measured) tensile strength and $\mathrm{Rm}_{\mathrm{NN}}$ is the predicted value from the neural network.

The results were presented in a typical plot "frequency versus error". The error had a classical Gaussian distribution around the zero value. For more than $95 \%$ of the test dataset the error of prediction was within $\pm 10 \%$. These results gave us a confidence that our model can predict with sufficient accuracy for the practice. 

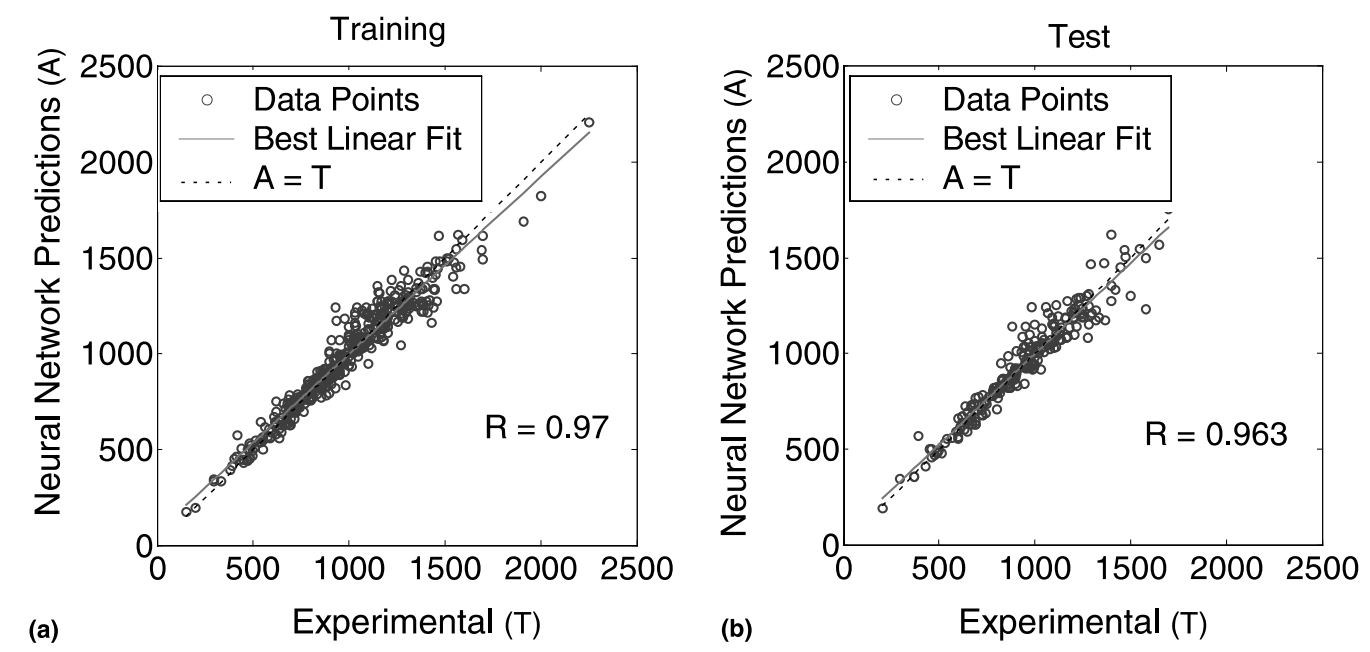

Fig. 4. Predicted tensile strength (MPa) from the neural network versus experimental values for the training (a) and test (b) data sets.

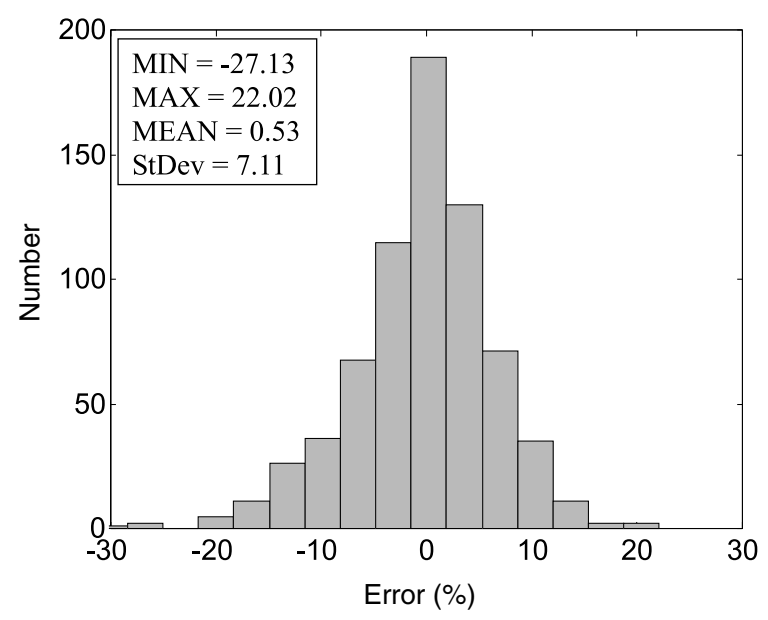

Fig. 5. Statistical analysis of the error of neural network predictions for the tensile strength.

\section{Results and discussion}

\subsection{Comparison of the prediction from the model and experimental data}

On the basis of artificial neural networks a model for simulation of the mechanical properties for titanium alloys was created. This model can be used to predict mechanical properties with suffi- cient accuracy within the range of the data set used in the training (see Tables 1-3 and Fig. 3). It should be reiterated here that the designed models are "statistical" models, i.e., they are not based on any physical theory. Because of this, some explanation of the results from the metallurgical point of view will be given.

In the following, mechanical properties for different titanium alloys and different heat treatment and temperature conditions are predicted by this model and thereafter analysed. Some of the results are compared with experimental data from the literature. All comparisons between neural network predictions and experimental data are for data pairs which have not been involved in the training process.

The tensile strengths for some of the most popular commercial titanium alloys were calculated (see Fig. 6) using the model. The predictions are performed for different heat treatment conditions and working temperatures. The neural network predictions are in good agreement with the experimental data. Similar correspondences were observed for the other mechanical properties. In fact, the accuracy of the neural network predictions was higher for the tensile test properties. This is due to the fact that the number of training data pairs was larger for the tensile properties as compared to the other mechanical properties 


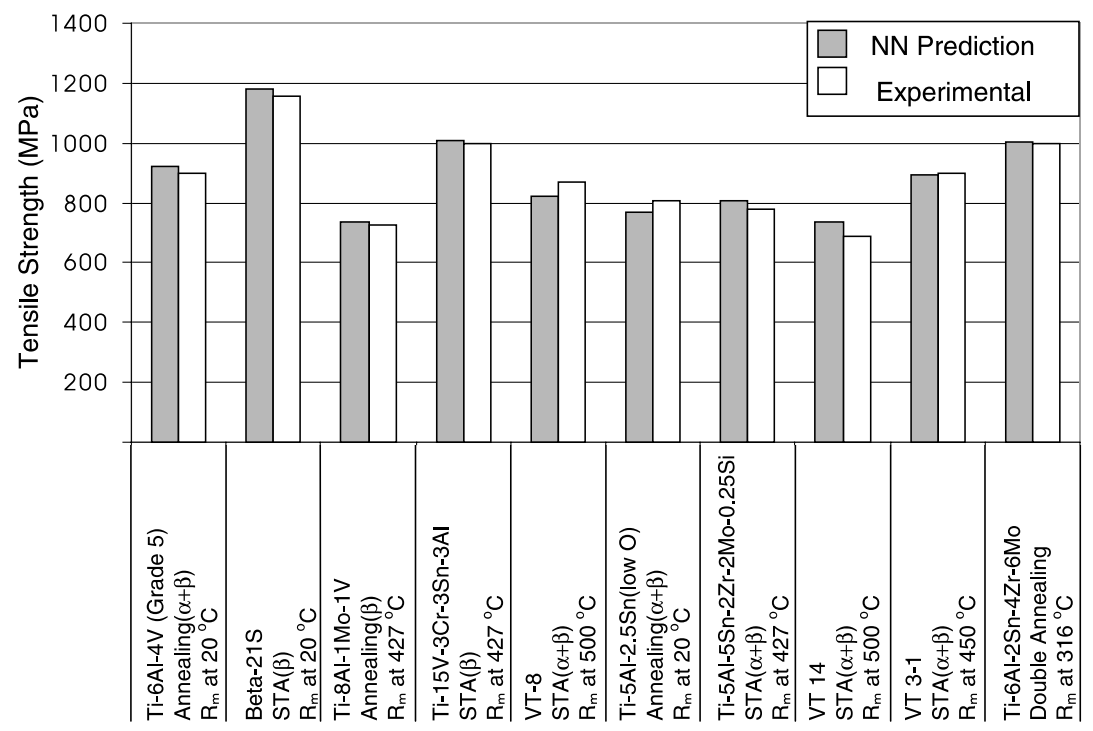

Fig. 6. Predictions from the neural network and experimental tensile strength for different alloys, heat treatments and operating temperatures.

(see Table 3). However, the accuracy of the neural network predictions was within acceptable error range for all other properties. Some uncertainty existed only regarding the prediction of the fracture toughness.

\subsection{Prediction of room temperature properties}

Since most of the data pairs used were for mechanical properties at room temperature the highest accuracy of the neural network is expected for the prediction of room temperature properties. Using the trained neural network, the mechanical properties for different titanium alloys at room temperature were predicted. The results are compared with experimental data published in different sources [1-4,11-16] (Fig. 7).

The very good agreement between the predicted values from the neural network and the experimental data for the different properties is obvious (Fig. 7). The difference between the neural network predictions and the experimental data is comparable with the difference between experimental data published in different sources. This gives us a confidence in the predictions from the model.

\subsection{Neural network predictions for mechanical properties at high and low temperatures}

Since operating temperature is another very important parameter in the application of titanium alloys, its influence was also studied by using the above model. The well-known high-temperature commercial alloys Ti-6Al-2Sn-4Zr-2Mo (Western) and VT-8 (Russian) were chosen. Their mechanical properties were calculated from the neural network model in the temperature range from $-200^{\circ} \mathrm{C}$ to $800^{\circ} \mathrm{C}$ (Fig. 8).

The predicted tensile and yield strength were not affected much when the temperature was increased from room temperature to $\sim 500^{\circ} \mathrm{C}$ for both alloys (see Figs. 8(a) and (b)). When the temperature was increased to above $600^{\circ} \mathrm{C}$ a significant decrease of tensile and yield strength was observed. From the results it can be concluded that the maximum operating temperature at which the strength properties are still kept stable is around $550^{\circ} \mathrm{C}$ which is in agreement with the recommendations in the literature for the temperature range of use for these alloys.

On the other hand, an increase in temperature results in significant increasing of the elongation 

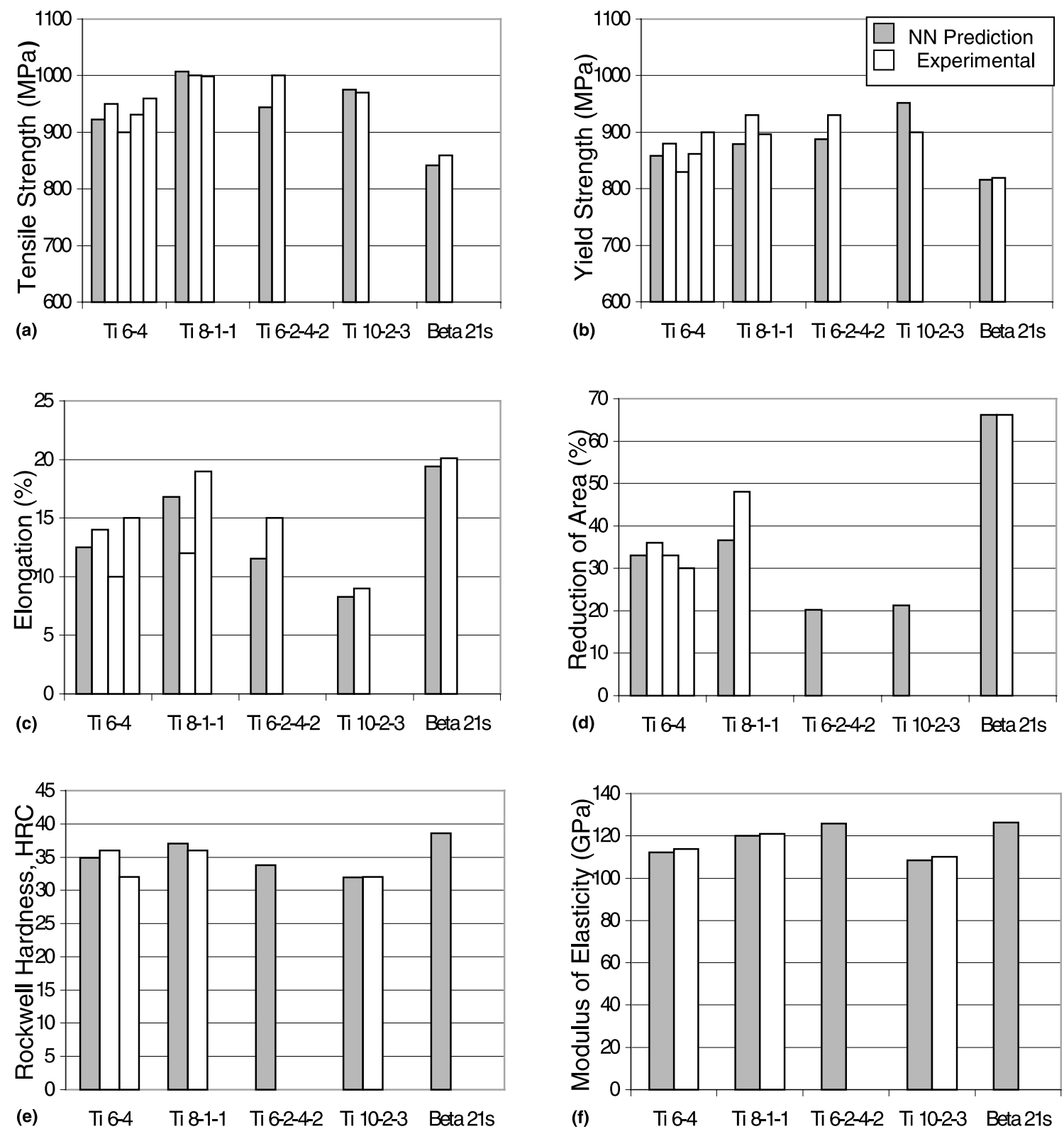

Fig. 7. Neural network predictions of mechanical properties at room temperature for different titanium alloys after $(\alpha+\beta)$ annealing: (a) tensile strength; (b) yield strength; (c) elongation; (d) reduction of area; (e) hardness; (f) modulus of elasticity.

(especially above $600^{\circ} \mathrm{C}$, see Fig. $8(\mathrm{c})$ ), the reduction of area (Fig. 8(d)) and the impact toughness (Fig. 8(e)).

At sub-zero temperatures naturally the influence was opposite. The strength properties were increased (Figs. 8(a), (b) and (f)) while the plas- ticity of the alloys was significantly decreased (Figs. 8(c), (d) and (e)). The effect of the temperature estimated from the trained neural network on the mechanical properties is consistent with what is expected from metallurgical point of view. 

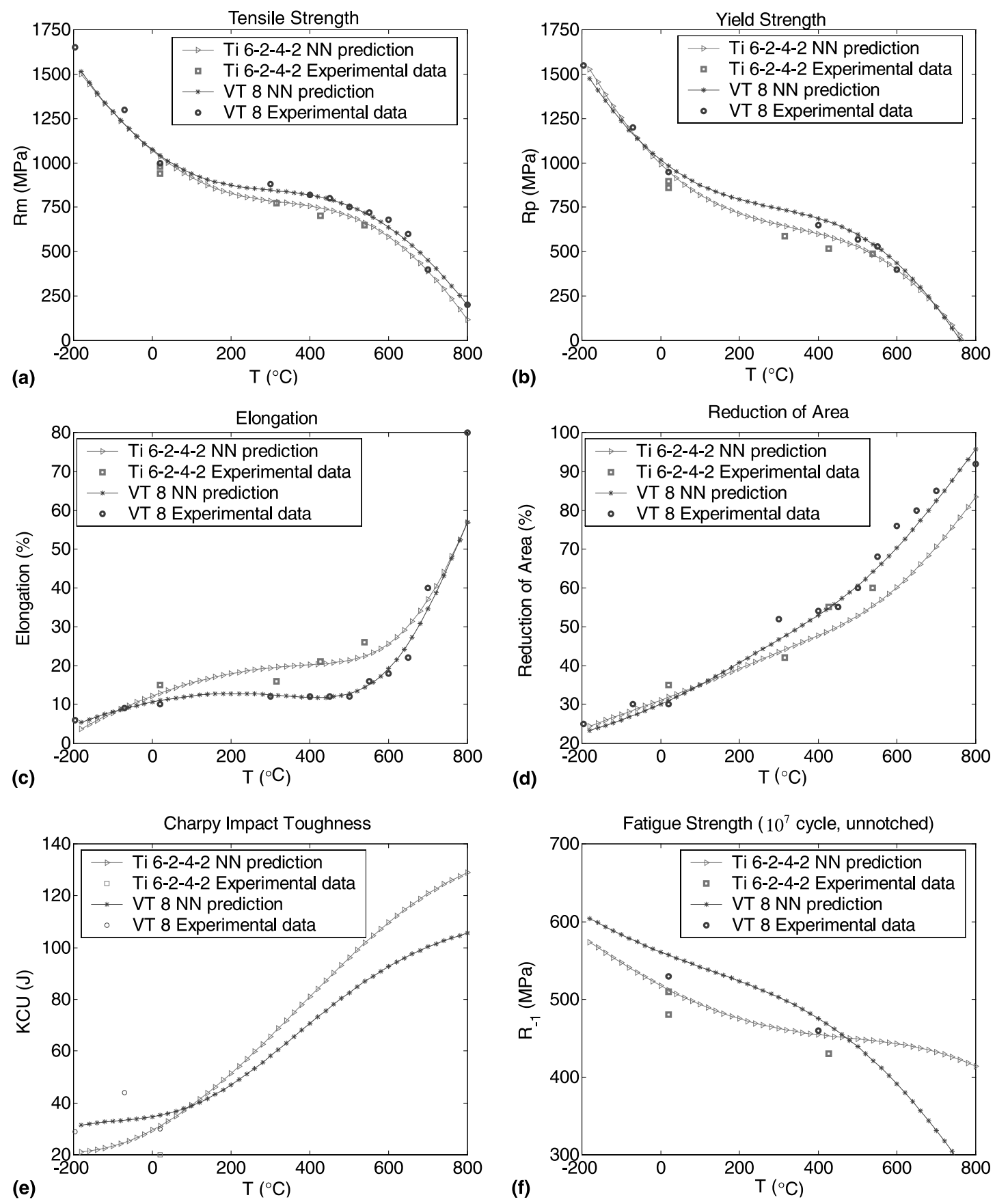

Fig. 8. Predicted from the neural network influence of the temperature on the mechanical properties for $\mathrm{Ti}-6 \mathrm{Al}-2 \mathrm{Sn}-4 \mathrm{Zr}-2 \mathrm{Mo}$ and VT-8 alloys after double annealing heat treatment. 
From Fig. 8 it is also obvious that the predicted temperature dependencies of the different mechanical properties match well with the experimental data.

\subsection{Neural network predictions for the heat treat- ment conditions}

The method of heat treatment is a significant process parameter. The optimization of the heat treatment in order to achieve desirable mechanical properties has major importance in titanium alloys practice. In the following the neural network predictions for the influence of heat treatment on mechanical properties will be discussed.

The effects of the most commonly used heat treatments for titanium alloys were studied. The influence of heat treatment was modelled for $\mathrm{Ti}-$ 8Al-1Mo-1V alloy (Fig. 9). A very good agreement between predicted and experimental tensile strength after different heat treatments was found. From the results it can be concluded that the neural network has been trained to "understand" the influence of the heat treatment on the microstructure and therefore on the properties of titanium alloys. It must be admitted, however, that the approach used is not purely quantitative re-

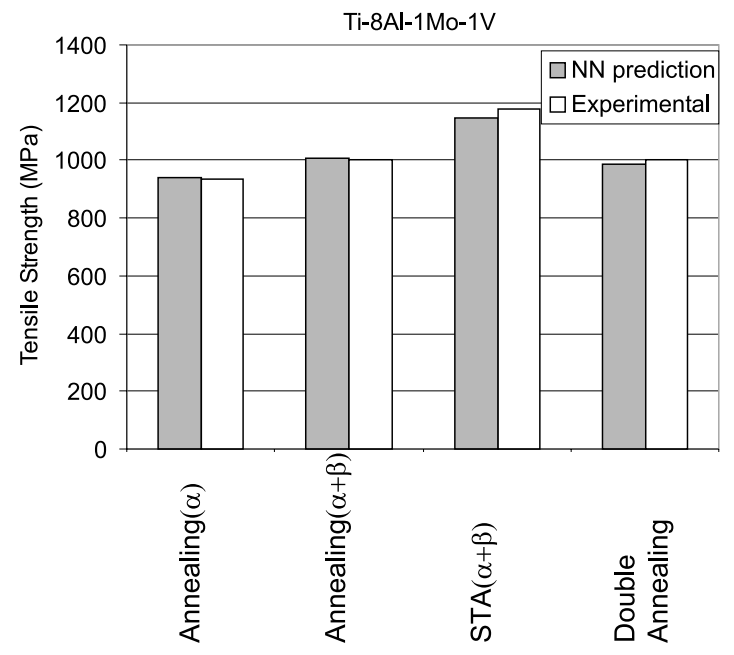

Fig. 9. Neural network predictions and experimental data for the tensile strength of Ti-8Al-1Mo-1V alloy after different heat treatments. garding the heat treatment. The heat treatment processes are considered only qualitatively. The particular heat treatment parameters such as temperature of heating, time, heating/cooling rates are not taken into account in the model. This implies the assumption that all data are at optimal heat treatment conditions for the corresponding heat treatment procedure $(\alpha+\beta$ annealing, solution treatment + ageing, etc.) and alloy.

The model would be more accurate and precise if the particular characteristics of the microstructure (type of phases present, grain size and grain shape, morphology and distribution of the fine microstructure, e.g., $\alpha+\beta$ colonies, texture, etc.) were involved as input parameter instead of simply the type of heat treatment. However, at present in the literature there are not enough data for training of such neural network.

Additionally we tried to model the influence of the ageing temperature on the mechanical properties. The tendency towards decreasing tensile strength was simulated when the ageing temperature was raised but the accuracy of prediction was not acceptable. Apparently more data for mechanical properties after ageing at different temperatures are needed to train the neural network to cope with this effect.

\subsection{Neural network predictions for alloy composi- tion}

The influence of aluminium (Figs. 10(a) and (c)) and vanadium (Figs. 10(b) and (d)) on the mechanical properties for one of the most popular titanium systems (Ti-Al-V) was modelled. Attention was paid to this system since it is well known that Ti-6Al-4V alloy is the most widely used titanium alloy. The mechanical properties were computed assuming increased and decreased content of aluminium and vanadium from the Ti-6Al$4 \mathrm{~V}$ composition in $\alpha+\beta$ annealing condition.

From the simulations it can be concluded that with increasing aluminium content both tensile strength and yield strength are increased appreciably (Fig. 10(a)). Simultaneously a very high influence of aluminium on the elongation (especially when the aluminium exceeds $8 \mathrm{wt} \%$ ) was found. A very small increase of the aluminium 

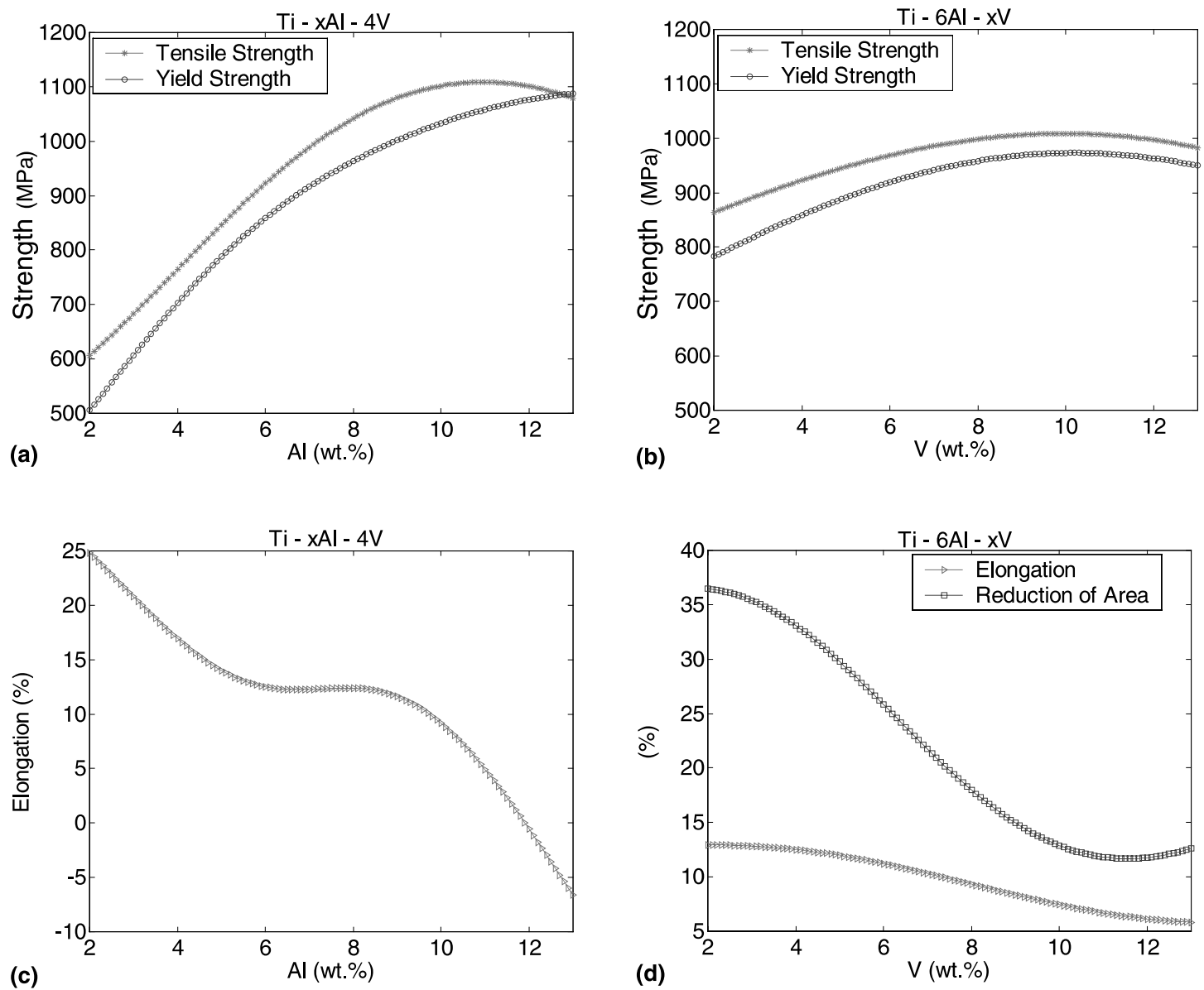

Fig. 10. Neural network predictions for the influence of the alloy composition on the mechanical properties for the $\mathrm{Ti}-x \mathrm{Al}-y \mathrm{~V}$ system: (a) tensile and yield strength for $\mathrm{Ti}-x \mathrm{Al}-4 \mathrm{~V}$; (b) tensile and yield strength for Ti-6 Al- $y \mathrm{~V}$; (c) elongation for $\mathrm{Ti}-x \mathrm{Al}-4 \mathrm{~V}$; (d) elongation and reduction of area for $\mathrm{Ti}-6 \mathrm{Al}-y \mathrm{~V}$.

content causes a significant decrease of the elongation (see Fig. 10(c)), approaching a value of zero when the aluminum content was as high as 11 $\mathrm{wt} \%$. The predicted effect of significant decrease of the ductility properties can be explained from the metallurgical point of view with the formation of the $\mathrm{Ti}_{3} \mathrm{Al}$ phase.

The influence of vanadium on the mechanical properties shows a similar tendency. With increasing vanadium content tensile strength and yield strength are increased (Fig. 10(b)) while the plasticity properties (elongation and reduction of area) are decreased (Fig. 10(d)). The vanadium influence on the tensile strength is much weaker as compared to the influence of aluminium.
The predicted dependencies on aluminium and vanadium are in accordance with the well-established influence of the above elements over the mechanical properties. From the metallurgical point of view, it is also not surprising that in general substitutional elements increase the strength properties in titanium alloys. The simulated results are therefore consistent with what is expected from the theory and practice of the titanium alloys.

The influence of other alloying elements like $\mathrm{Mo}, \mathrm{Sn}, \mathrm{Zr}, \mathrm{Fe}$ and oxygen was also studied. Different tendencies for the influence of the different alloying elements on the mechanical properties were found. Hence, the trained neural 
network can be used for optimization of the alloy composition in order to obtain the desired combination of properties.

\section{Use of the model for optimization of the alloy composition and processing parameters}

Based on the trained neural network a computer program for optimization of the alloy composition and processing parameters was designed (Fig. 11), using a simple grid search. The input parameters of the program are the optimization criteria such as desired property (or combination of properties) at any conditions. The trained neural network is incorporated in the body of the program. Loops are organized for alloy composition, heat treatments and temperature. For each combination of inputs (alloy composition, heat treatments and temperature), the output values are predicted from the neural network and compared with the input criteria. As a result of these computations the "best" solution in respect to alloy composition and/or heat treatment corresponding to the desired properties

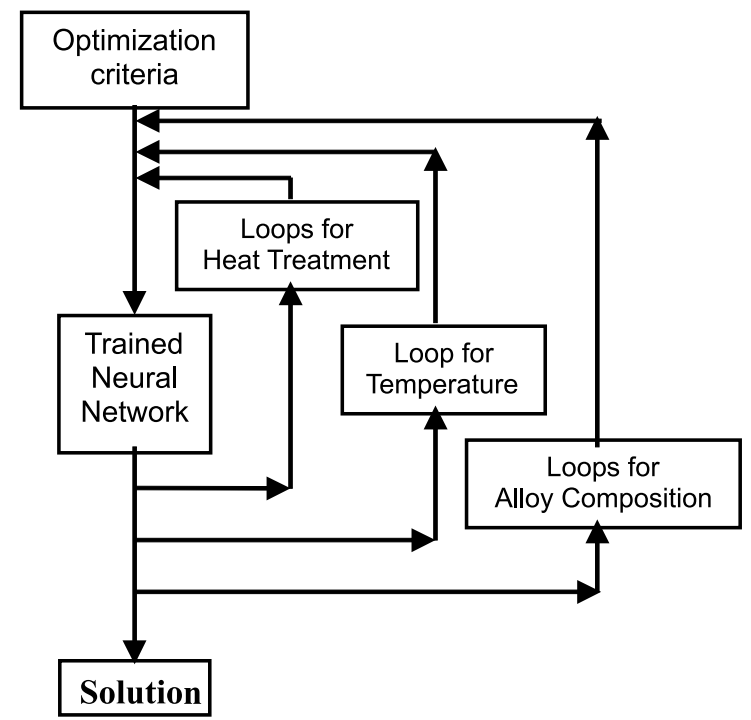

Fig. 11. Block diagram of computer program for optimization of the alloy composition and heat treatment conditions as a function of the desired properties and working temperature. is obtained at the output. In the following one example simulated from the program is demonstrated:

\section{Example}

Find: Alloy composition with maximal tensile strength $(\mathrm{Rm})$ at $420^{\circ} \mathrm{C}$.

Fix: Heat treatment $-\alpha+\beta$ annealing; $T=$ $420^{\circ} \mathrm{C}$; zero amount of $\mathrm{Sn}, \mathrm{Cr}, \mathrm{Fe}, \mathrm{Si}, \mathrm{Nb}$, $\mathrm{Mn} ; \mathrm{O}=0.12$

Vary: Al, Mo, Zr, V

Solution: The optimal composition is $\mathrm{Al}=5.8$ $\mathrm{wt} \%, \mathrm{Mo}=7.3 \mathrm{wt}^{\%} \%, \mathrm{Zr}=5.2 \mathrm{wt} \%, \mathrm{~V}=0 \mathrm{wt} \%$; This composition gives tensile strength at $420^{\circ} \mathrm{C}-\operatorname{Rm}\left(420^{\circ} \mathrm{C}\right)=932 \mathrm{MPa}$. The other mechanical properties at $420^{\circ} \mathrm{C}$ are: $\operatorname{Rp}\left(420^{\circ} \mathrm{C}\right)=$ $665 \mathrm{MPa} ; E\left(420^{\circ} \mathrm{C}\right)=10 \% ; \operatorname{ME}\left(420^{\circ} \mathrm{C}\right)=94$ $\mathrm{GPa} ; \quad R_{-1}\left(420^{\circ} \mathrm{C}\right)=448 \mathrm{MPa} ; \quad K_{1 \mathrm{c}}\left(420^{\circ} \mathrm{C}\right)=$ $101 \mathrm{MPa} \mathrm{m}^{1 / 2}$.

The above program can be used to find a solution for "best" alloy composition and processing parameters for arbitrarily optimization criteria or combination of optimization criteria. In future, more efficient optimization methods can be incorporated [30].

\section{Graphical user interface}

On the base of the designed model of artificial neural network a graphical user interface (GUI) was created (Fig. 12) for easy further use of the model. On input of the chemical composition of the titanium alloys, temperature interval and the heat treatment the chosen mechanical property is simulated and plotted. In this way, the user can very easily obtain the temperature dependence of any from the nine mechanical properties involved in the model for any heat treatment conditions and arbitrarily alloy composition. Furthermore, the GUI provides opportunity for easy comparison of mechanical properties corresponding to different conditions by plotting them together. An option is incorporated where the mechanical properties can be calculated and plotted versus the amount of a chosen alloying element at any fixed temperature. The GUI also allows easy switch between the different heat treatments and mechanical properties. In this way, the user can 


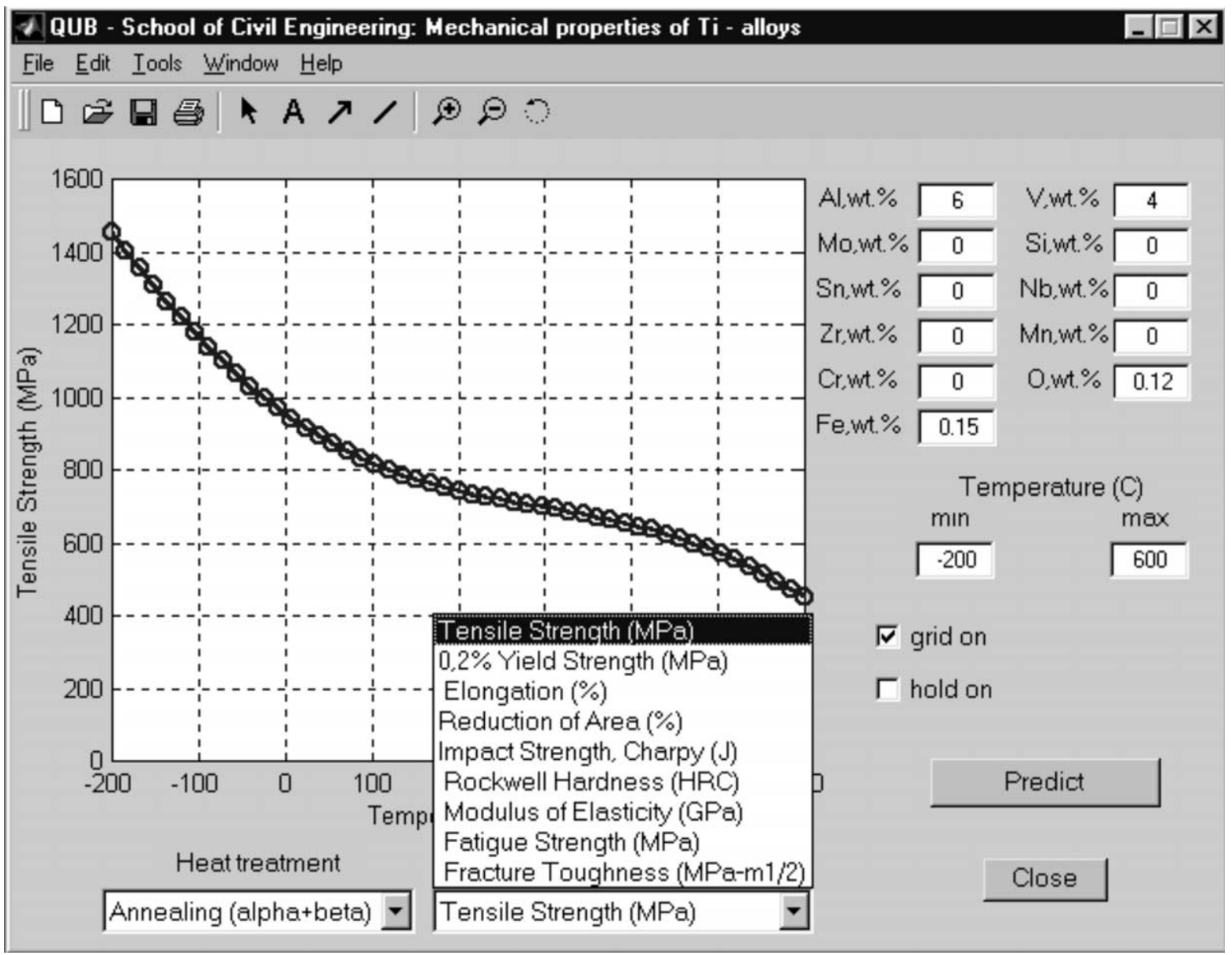

Fig. 12. GUI for prediction of mechanical properties of titanium alloys as a function of alloy composition, heat treatment and operating temperature.

analyse the influence of the different factors (heat treatments and alloy composition) on the different mechanical properties at different operating temperatures. It should be noted here that the program will work with appropriate accuracy within the range of the data set used for training of the neural network.

\section{Summary and conclusions}

An artificial neural network model has been created for the prediction of the mechanical properties of titanium alloys as functions of the alloy composition, heat treatment conditions and working temperature. The model has been used to study the influence of different factors on the mechanical properties in titanium alloys.

A GUI for use of the model has been created. The program and the model can be used for:

- prediction of mechanical properties for titanium alloys as functions of their chemical composition, heat treatment conditions and working temperature,

- investigation of the influence of different factors on the mechanical properties in titanium alloys,

- optimization of the alloy composition and processing parameters.

The authors believe that the proposed model is convenient and powerful tool for practical 


\section{$0,2 \%$ Yield Strength}
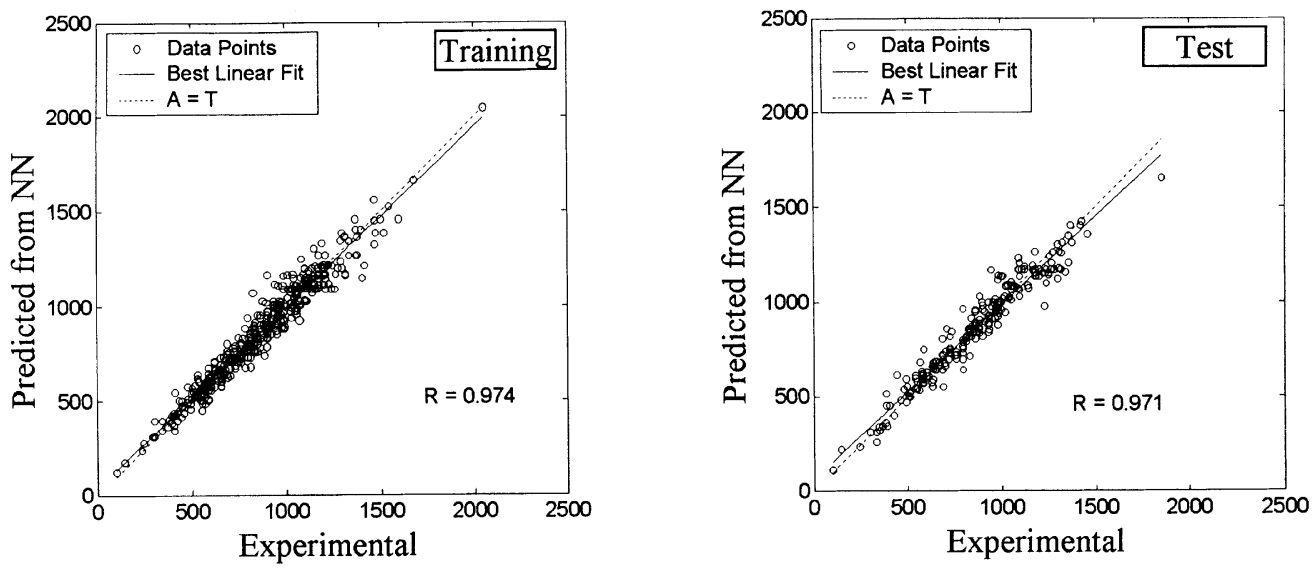

\section{Elongation}
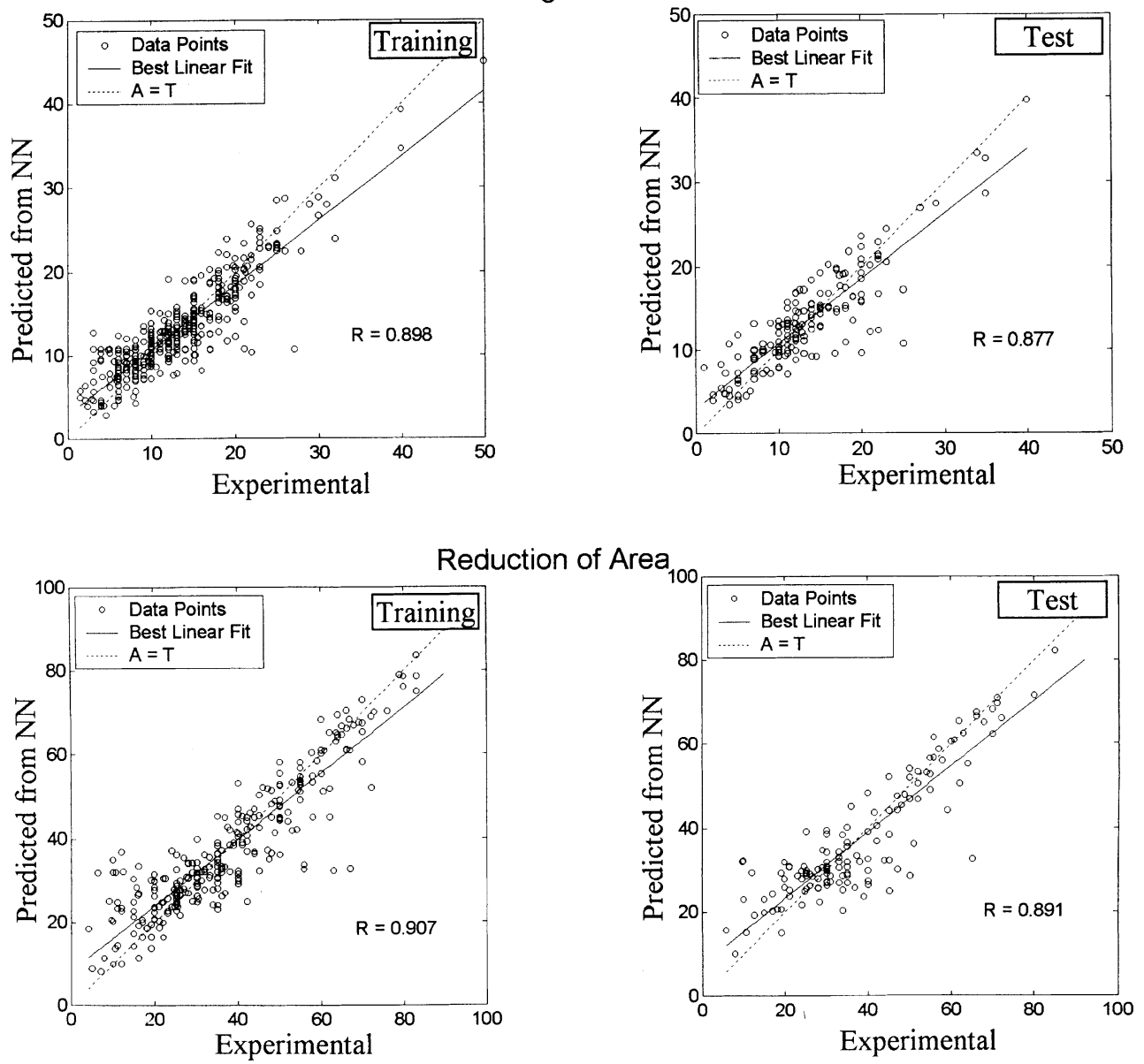

Fig. 13. 


\section{Impact Strength}
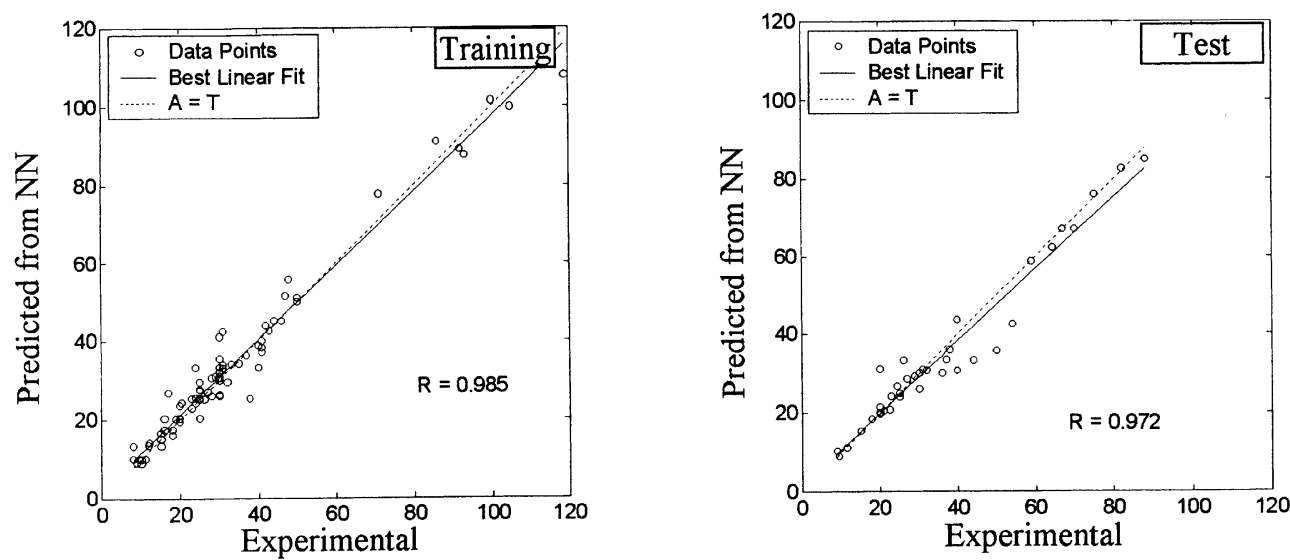

Rockwell Hardness
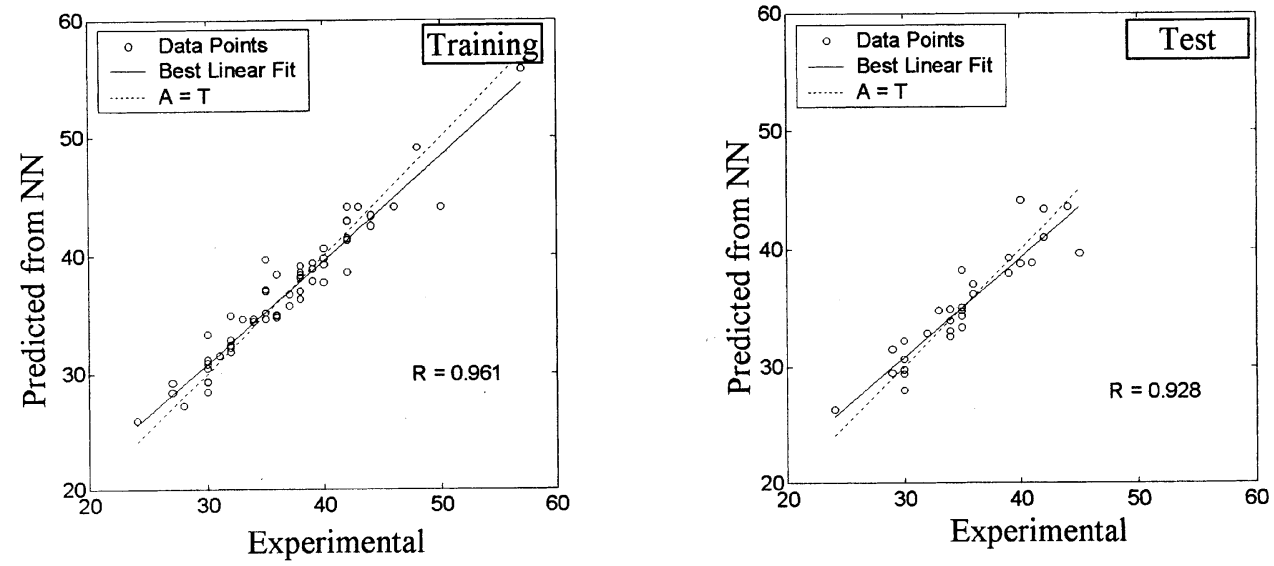

Modulus of Elasticity
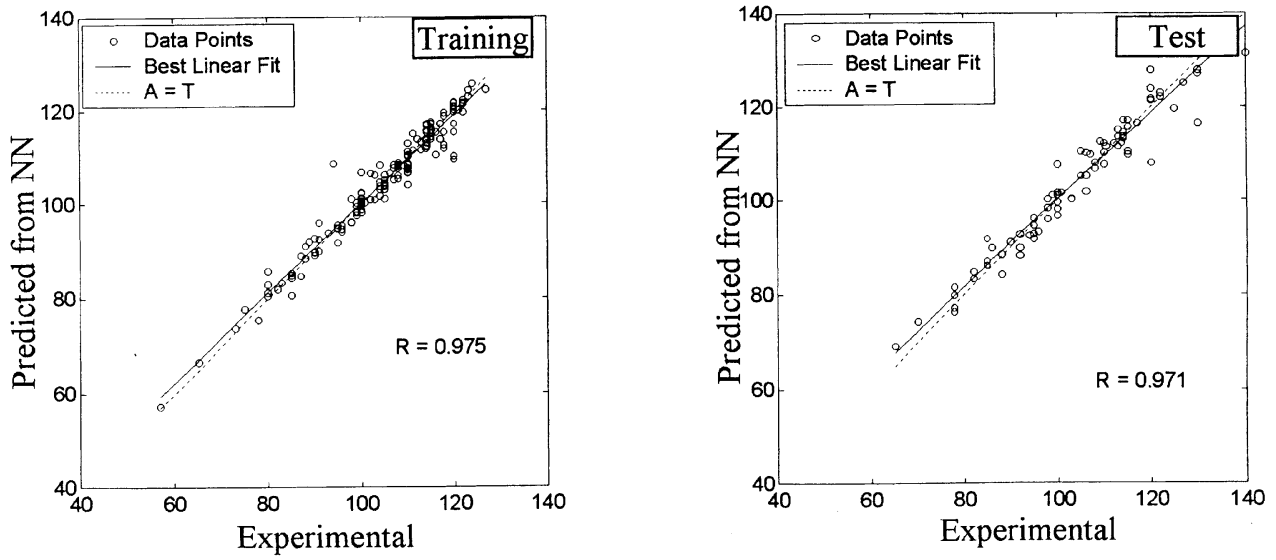

Fig. 13. (Continued). 
Fatigue Strength
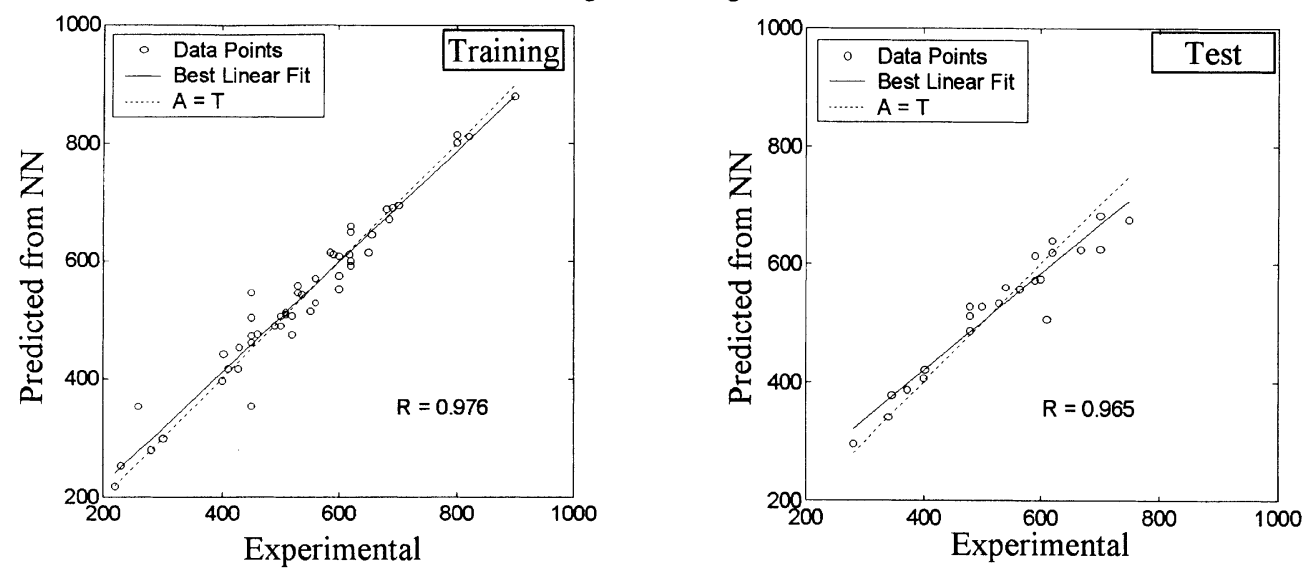

Fig. 13. (Continued).

optimization of the alloy composition and processing parameters of titanium alloys in order to obtain the desired combination of properties at different working temperatures. The model is open for constant upgrade and improvement.

\section{Appendix A}

List of the alloys used for training and test of artificial neural network for prediction of mechanical properties of titanium alloys

Ti-6Al-2Sn-1.5Zr-1Mo-0.35Bi-0.1Si, Ti-6Al$2 \mathrm{Nb}-1 \mathrm{Ta}-0.8 \mathrm{Mo}, \quad \mathrm{Ti}-6 \mathrm{Al}-2 \mathrm{Nb}-1 \mathrm{Ta}-1 \mathrm{Mo}, \quad \mathrm{Ti}-$ $6 \mathrm{Al}-1 \mathrm{Mo}-2 \mathrm{Nb}-1 \mathrm{Ta}, \mathrm{Ti}-3 \mathrm{Al}-2.5 \mathrm{~V}$, Ti-5Al-2.5Sn, Ti-5Al-2Zr-2Mo-0.25Si, Ti-6Al-2Sn-4Zr-2Mo, Ti-6Al-2Sn-4Zr-2Mo-0.1Si, Ti-1Sn-5Zr-2.25Al$1 \mathrm{Mo}-0.25 \mathrm{Si}$, Ti-8Al-1Mo-1V, IMI 834, IMI 417, Titanium 1100, Ti-10V-2Fe-3Al, Ti-11.5Mo-Zr4.5Sn, Ti-3Al-8V-6Cr-4Mo-4Zr, Ti-12V-2.5Al2Sn-6Zr, Ti-15Mo-5Zr, $\beta-21 \mathrm{~S}, \quad \mathrm{Ti}-11.5 \mathrm{~V}-2 \mathrm{Al}-$ 2Sn-11Zr, Ti-13V-11Cr-3Al, Ti-13V-2.7Al-7Sn2Zr, Ti-15V-3Cr-3Al-3Sn, Ti-15Mo-5Zr-3Al, Ti-8Mo-8V-2Fe-3Al, $\beta$-CEZ, Ti-4.5Al-5Mo$1.5 \mathrm{Cr}$ (Corona 5), Ti-8Mn, Ti-5Al-2Sn-2Zr$4 \mathrm{Mo}-4 \mathrm{Cr}$ (Ti-17), Ti-6Al-2Sn-2Zr-2Mo-2Cr0.25Si, Ti-4Al-4Mo-2Sn-0.5Si (IMI550), Ti6Al-2Sn-4Zr-6Mo, Ti-6Al-4V, Ti-6Al-6V-2Sn, Ti-7Al-4Mo, Ti-5Al-5Sn-2Zr-2Mo-0.25Si, Ti5Al-3.5Sn-3Zr-1Nb-0.3Si, $\quad$ Ti-5Al-6Sn-2Zr-
$1 \mathrm{Mo}-0.25 \mathrm{Si}, \quad \mathrm{Ti}-6 \mathrm{Al}-1.7 \mathrm{Fe}-0.1 \mathrm{Si}, \quad \mathrm{Ti}-4.5 \mathrm{Al}-3 \mathrm{~V}-$ 2Mo-2Fe, Ti-6Al-7Nb, Ti-4Al-4Mo-4Sn-0.5Si, Ti-4Al-3Mo-1V, Ti-5Al-1.5Fe-1.4Cr-1.2Mo, Ti5Al-2.5Fe, Ti-6.4Al-1.2Fe, Ti-2Fe-2Cr-2Mo, Ti-8V-5Fe-1Al, Ti-16V-2.5Al, Ti-3Al-1.5Cr1.5Fe, Ti-6Al-2Fe, Ti-6Al-2Fe-0.1Si, Ti-6Al1Fe-1Cr, Ti-8Al-2Fe, VT14, VT15, VT16, VT18, VT20, VT22, OT4, VT1-00, VT3-1, VT5, VT5-1, VT-6, VT-6C, VT-8, VT-9.

\section{Appendix B}

Predicted mechanical properties from the neural network (A) versus experimental values $(\mathrm{T})$ for the training and test data sets are presented in Fig. 13.

\section{References}

[1] R. Boyer, G. Welsch, E.W. Collings, Materials Properties Handbook: Titanium Alloys, ASM International, Materials Park, OH, 1994.

[2] R.A. Wood, R.J. Favor (Eds.), Titanium Alloys Handbook, Metals and Ceramics Information Center, Batelle Publication No. MCIC-HB02, OH, 1972.

[3] P.A. BlenkinsopW.J. Evans, H.M. Flower (Eds.), Titanium'95: Science and Technology, Proceedings of the Eight World Conference on Titanium, The Institute of Materials, London, UK, 1996.

[4] J.C. Williams, A.F. Belov (Eds.), Titanium and Titanium Alloys: Scientific and Technological Aspects, Proceedings 
of the Third International Conference on Titanium, Plenum Press, New York, 1982.

[5] S. Bein, J. Bechet, Journal de Physique IV 6 (C1) (1996) 99.

[6] E. Laude, E. Gautier, S. Denis, in: P.A. Blenkinsop, W.J. Evans, H.M. Flower (Eds.), Titanium'95: Science and Technology, Proceedings of the Eight World Conference on Titanium, The Institute of Materials, London, UK, 1996, pp. 2330-2337.

[7] S. Malinov, P. Markovsky, W. Sha, Z. Guo, J. Alloy Compd. 314 (2001) 181.

[8] S. Malinov, Z. Guo, W. Sha, Z.X. Guo, A.F. Wilson, in: M. Winstone (Ed.), Titanium Alloys at Elevated Temperature: Structural Development and Service Behaviour, Conference Proceedings, The Institute of Materials, London, UK, 2001, pp. 69-88.

[9] S. Malinov, W. Sha, Z. Guo, A. Wilson, Metall. Mater. Trans. A 32A (2001) 879.

[10] S. Malinov, W. Sha, Z. Guo, Mater. Sci. Eng. A 283 (2000) 1.

[11] R.I. Jaffee, N.E. Promisel (Eds.), The Science, Technology and Application of Titanium, Pergamon Press, Edinburgh, UK, 1970.

[12] M. John, C.Y. Ho (Eds.), Structural Alloys Handbook, CINDAS/Purdue University, West Lafayette, IN, 1996.

[13] Metals Handbook, Vol. 2 - Properties and Selection: Nonferrous Alloys and Special-Purpose Materials, 10th ed., ASM International, Materials Park, OH, 1990.

[14] M. Bauccio (Ed.), Metals Reference Book, 3rd ed., ASM International, Materials Park, OH, 1994.

[15] W.F. Smith, Structure and Properties of Engineering Alloys, McGraw-Hill, USA, 1993.
[16] S.B. Maslenkov, E.A. Maslenkova, Stali i splavi dlia visokih temperatur, Moskva, Metallurgia (1991).

[17] H.K.D.H. Bhadeshia, ISIJ Int. 39 (1999) 966.

[18] T. Cool, H.K.D.H. Bhadeshia, D.J.C. McKay, Mater. Sci. Eng. A 223 (1997) 186.

[19] H. Fujii, D.J.C. McKay, H.K.D.H. Bhadeshia, ISIJ Int. 36 (1996) 1373

[20] J.J. Wang, P.J. van der Wolk, S. van der Zwaag, ISIJ Int. 39 (1999) 1038

[21] W.G. Vermeulen, P.J. van der Wolk, A.P. de Weijer, S. van der Zwaag, J. Mater. Eng. Perform. 5 (1996) 57.

[22] F. Tancret, H.K.D.H. Bhadeshia, D.J.C. McKay, ISIJ Int. 39 (1999) 1020.

[23] V. Narayan, R. Abad, B. Lopez, H.K.D.H. Bhadeshia, D.J.C. McKay, ISIJ Int. 39 (1999) 999.

[24] H. Fujii, D.J.C. McKay, H.K.D.H. Bhadeshia, H. Harada, K. Nogi, J. Jpn. I. Met. 63 (1999) 905.

[25] S.B. Singh, H.K.D.H. Bhadeshia, D.J.C. McKay, H. Carey, I. Martin, Ironmaking Steelmaking 25 (1998) 355.

[26] S. Yoshitake, V. Narayan, H. Harada, H.K.D.H. Bhadeshia, D.J.C. McKay, ISIJ Int. 38 (1998) 495.

[27] L.A. Dobizanski, W. Sitek, J. Mater. Process. Tech. 78 (1998) 59.

[28] L. Rawtani, J.L. Rana, A.K. Tiwari, Comput. Mater. Sci. 15 (4) (1999) 493.

[29] R.P. Lippmann, IEEE ASSP Mag. 4 (1987) 4.

[30] J.J. McKeown, D. Sprevak, D. Meegan, An Introduction to Unconstrained Optimization, Adam Hilger, Bristol, 1990.

[31] J.J. McKeown, F. Stella, G. Hall, Neural Net. 10 (1997) 1455. 